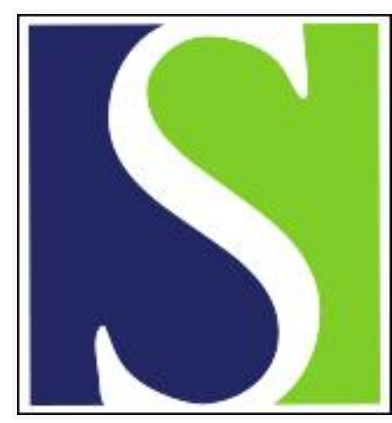

Scand J Work Environ Health 2017;43(6):505-508

https://doi.org/10.5271/sjweh.3681

Published online: 18 Oct 2017, Issue date: 01 Nov 2017

\title{
Environmental noise and breast cancer risk?
}

by Hansen J

Affiliation: Danish Cancer Society Research Center, Copenhagen, Denmark. johnni@cancer.dk

Refers to the following text of the Journal: 2017;43(6):509-518

Key terms: aircraft noise; breast cancer; breast cancer risk; breast neoplasm; cancer; editorial; environmental noise; epidemiology; estrogen; estrogen receptor; exposure; noise; railway noise; road noise; traffic noise; transportation

This article in PubMed: www.ncbi.nlm.nih.gov/pubmed/29043372 


\section{Editorial}

Scand J Work Environ Health. 2017;43(6):505-508. doi:10.5271/sjweh.3681

\section{Environmental noise and breast cancer risk?}

Breast cancer is the most frequent cancer among women especially in the Western world where, despite improved survival, it is one of the leading causes of death (1). Furthermore, for several decades there has been an increase in incidence, though recently there seems to be a stabilization in risk or even a small decline in typical high-risk areas such as Europe and the USA but at the same time a steep increase in typical low-risk societies such as Japan (2).

Breast cancer is often regarded as a singular disease, but recent discoveries are pointing to a variety of types of potentially different etiology. Thus, the female breast undergoes substantial changes beginning from the time in the fetus and throughout life, especially in response to hormonal changes during puberty, pregnancy, lactation and menopause. Consequently, breast tumors are often characterized by at least the status of, for example, menopause and by functional hormonal receptors, such as estrogen receptor positive (ER+) or estrogen receptor negative (ER-) (3).

The causes of breast cancer have been explored during many decades, and especially sex hormones play a pivotal role in the most established risk factors such as early menarche, late menopause, nulliparity, late first pregnancy, oral contraceptives, and hormone replacement therapy. Overall, however, these and other established risk factors for breast cancer explain only a minor fraction of the diseases (4). Non-hormonal avenues of potential risk factors for breast cancer have also been pursued. Recently, the International Agency for Research on Cancer (IARC) classified shiftwork that involves circadian disruption as a probable cause for human breast cancer, and the evidence for this association is mounting (5). Further, even exposure to ill-timed light-at-night beyond night work, ie, social jetlag and living in highly lit urban areas, may be associated with breast cancer (6).

It has recently been suggested that exposure to ambient noise may also be involved in breast cancer risk. Noise is defined as unwanted and unpleasant sounds, and apparently evolution has programmed humans and animals to be aware of high sounds as possible sources of danger. Thus, traffic noise from aircrafts, cars, railways and trains are relatively new environmental pollutants, which have expanded after World War II and are now widespread especially in urban areas and around airports. It is well documented that loud noise can cause hearing loss. It is also well known that nocturnal noise disturbs both the length and quality of sleep (7). The evidence supporting the long-term non-auditorial effects from noise, however, remains to be established (8).

In 2005 Visser et al (9) first reported on noise exposure and cancer incidence, including breast cancer, in an ecological study of people living around Schiphol international airport in The Netherlands. The estimated relative risk of breast cancer was close to unity when compared to the reference population of The Netherlands. Two similar studies of residents near the airport of Cologne-Bonn and residents in Bremen exposed to noise from road traffic, railroads, and aircrafts found increased risk of breast cancer in the subgroup with the highest estimated aircraft noise levels, although only adjusted for age and socioeconomic status $(10,11)$. A Danish cohort of post-menopausal woman, adjusted for most potential confounders, observed no overall breast cancer risk for either noise from road traffic or railways (12). In secondary analyses of the relatively rare ER- breast cancer, exposure to both residential road traffic and railway noise was elevated, including a linear dose-response relationship (12). Based on the same cohort, no association between road traffic noise and either overall mortality or breast-cancer-specific mortality was found in the 1759 breast cancer cases (13). 
In this issues of the Journal, Hegewald et al (14) reports on breast cancer risk among women aged $\geq 40$ years, thus both pre- and postmenopausal women, in relation to exposure to aircraft, road and railway noise among residents near Frankfurt international airport in Germany. In contrast to the study from Denmark, only exposure to aircraft noise was clearly increased, whereas exposure to noise from road traffic and railways was not. Aircraft noise was also assessed in the Danish study, but the results were not reported separately. Interestingly, the increased breast cancer risk was only present for the ERsubgroup in both the German and the Danish studies. Whether this is random remains to be explored in future studies.

The shorter sleep among persons who are exposed to nocturnal noise has been suggested to be implicated in the link between noise and breast cancer risk. There is, however, no consistent elevated risk for breast cancer observed among women with short sleep duration. Thus, a recent meta-analysis based on seven studies estimated a relative risk of breast cancer close to unity (15), and same tendency is seen for hormone-related cancers, including breast cancer and cancer in general in another meta-analysis (16). Also the most recent meta-analysis by Erren et al (17) confirms no association between "poor sleep" and breast cancer risk (17). Finally, no association between sleep duration and breast cancer prognosis has been found among breast cancer survivors (18). Interestingly, Wang et al (19) observed a significantly increased risk for breast cancer primarily among Chinese premenopausal women who slept $\leq 6$ hours per day, but this observation was only seen in the subgroup of night shift-workers and not for women with short sleep duration who had never done night shift-work (19). This indicates that mechanisms primarily related to night work and menopausal status, rather than short sleep duration in general may be involved in the observed increased breast cancer risk. Therefore, it is suggested that future studies on noise and cancer adjust for exposure to night shiftwork and menopausal status.

Melatonin is a strong antioxidant and may also have other oncostatic effects (20), and marginally decreased melatonin levels are observed among women during night shift work (21). Low melatonin due to decreased sleep among people exposed to nocturnal noise exposure has been suggested as a potential mechanism for breast cancer (12), but this effect may be minimal, if at all, because decreased melatonin is caused by ill-timed light exposure and not by short sleep duration or noise. Further, melatonin has anti-estrogenic effects and inhibits the proliferation of ER+ breast cancer cells, which is why it should be expected that primarily this subtype of breast cancer should be elevated, thus in contrast to the observations in the Danish and recent German studies. Further, it has recently been indicated that short sleep duration has no effect on circadian disruption, which is suggested as a main pathway between nightwork and breast cancer (22). Stress may also follow noise exposure and has also been suggested as a risk factor for breast cancer, but perceived stress and low levels of estrogens have been associated with decreased breast cancer risk in Denmark (23).

Environmental air pollution - including exposure to polyaromatic hydrocarbons (PAH), which may be correlated with traffic noise (24) - has also been suggested as a risk factor for breast cancer (25), though the association is not clear (26). Regardless, attempts to adjust for this obvious potential confounder should also be included in future studies on noise and cancer.

Investigation of noise and breast cancer is at an early phase. There are only few studies, including somewhat inconsistent results both regarding type of noise exposure and breast cancer subtypes, and results have not been adjusted for the potential effect of exposure to traffic exhaust or light-at-night. Moreover, proposed biological mechanisms, such as short sleep or low levels of melatonin are not supported by epidemiologic results for breast cancer. Therefore, the current evidence for noise exposure and breast cancer appears inadequate. However, because exposure to ambient traffic noise is widespread and breast cancer is a frequent disease, new well-designed studies on this issue, including better adjustment for potential confounders, should be considered. 


\section{References}

1. Ferlay J, Soerjomataram I, Dikshit R, Eser S, Mathers C, Rebelo M, et al. Cancer incidence and mortality worldwide: sources, methods and major patterns in GLOBOCAN 2012. Int J Cancer. 2015;136(5):E359-86. https://doi.org/10.1002/ ijc. 29210

2. Ginsburg O, Bray F, Coleman MP, Vanderpuye V, Eniu A, Kotha SR, et al. The global burden of women's cancers: a grand challenge in global health. Lancet. 2017;389(10071):847-60. https://doi.org/10.1016/S0140-6736(16)31392-7

3. Akram M, Iqbal M, Daniyal M, Khan AU. Awareness and current knowledge of breast cancer. Biol Res. 2017;50(1):33. https://doi.org/10.1186/s40659-017-0140-9

4. Rojas K, Stuckey A. Breast cancer epidemiology and risk factors. Clin Obstet Gynecol. 2016;59(4):651-72. https://doi. org/10.1097/GRF.0000000000000239

5. Hansen J. Night shift work and risk of breast cancer. Curr Environ Health Rep. 2017. https://doi.org/10.1007/s40572017-0155-y

6. Lunn RM, Blask DE, Coogan AN, Figueiro MG, Gorman MR, Hall JE, et al. Health consequences of electric lighting practices in the modern world: A report on the National Toxicology Program's workshop on shift work at night, artificial light at night, and circadian disruption. Sci Total Environ. 2017;607-608:1073-84. https://doi.org/10.1016/j. scitotenv.2017.07.056

7. Basner M, Babisch W, Davis A, Brink M, Clark C, Janssen S, et al. Auditory and non-auditory effects of noise on health. Lancet. 2014;383(9925):1325-32. https://doi.org/10.1016/S0140-6736(13)61613-X

8. Halperin D. Environmental noise and sleep disturbances: A threat to health? Sleep Sci. 2014;7(4):209-12. https://doi. org/10.1016/j.slsci.2014.11.003

9. Visser O, van Wijnen JH, van Leeuwen FE. Incidence of cancer in the area around Amsterdam Airport Schiphol in 19882003: a population-based ecological study. BMC Public Health. 2005;5:127. https://doi.org/10.1186/1471-2458-5-127

10. Greiser EG, C;. Bösartige Neubildungen und Fliglärm und Abschlussbeicht über eine Fall-Kontroll-Studie im Umkreis des Flughafens Köln-Bonn. [Malignant neoplasms and aircraft noise- a report on a case-control study in the vicinty of the Cologne-Bonn Airport]. Musweiler: Epi. Consult Gmbh, 2009.

11. Greiser EG, C. Umbegebungslärm und Gesundheit am Beispiel Bremen Forschungkenzahl 371061170 (UBA- FB 002168). [Environmental noise and health in Bremen, Research identification number 371061170 (UBA- FB 002168)]. Umweltbundesamt: 2015.

12. Sorensen M, Ketzel M, Overvad K, Tjonneland A, Raaschou-Nielsen O. Exposure to road traffic and railway noise and postmenopausal breast cancer: A cohort study. Int J Cancer. 2014;134(11):2691-8. https://doi.org/10.1002/ijc.28592

13. Roswall N, Bidstrup PE, Raaschou-Nielsen O, Jensen SS, Olsen A, Sorensen M. Residential road traffic noise exposure and survival after breast cancer - A cohort study. Environ Res. 2016;151:814-20. https://doi.org/10.1016/j.envres.2016.09.016

14. Hegewald J, Schubert M, Wagner M, Droge P, Prote U, Swart E, et al. Breast cancer and exposure to aircraft, road, and railway-noise: a case-control study based on health insurance records. Scand J Work Environ Health. 2017;43(6):509-518. https://doi.org/10.5271/sjweh.3665

15. He C, Anand ST, Ebell MH, Vena JE, Robb SW. Circadian disrupting exposures and breast cancer risk: a meta-analysis. Int Arch Occup Environ Health. 2015;88(5):533-47. https://doi.org/10.1007/s00420-014-0986-x

16. Zhao H, Yin JY, Yang WS, Qin Q, Li TT, Shi Y, et al. Sleep duration and cancer risk: a systematic review and meta-analysis of prospective studies. Asian Pac J Cancer Prev. 2013;14(12):7509-15. https://doi.org/10.7314/APJCP.2013.14.12.7509

17. Erren TC, Morfeld P, Foster RG, Reiter RJ, Gross JV, Westermann IK. Sleep and cancer: Synthesis of experimental data and meta-analyses of cancer incidence among some 1,500,000 study individuals in 13 countries. Chronobiol Int. 2016;33(4):325-50. https://doi.org/10.3109/07420528.2016.1149486

18. Marinac CR, Nelson SH, Flatt SW, Natarajan L, Pierce JP, Patterson RE. Sleep duration and breast cancer prognosis: perspectives from the Women's Healthy Eating and Living Study. Breast Cancer Res Treat. 2017;162(3):581-9. https://doi. org/10.1007/s10549-017-4140-9

19. Wang P, Ren FM, Lin Y, Su FX, Jia WH, Su XF, et al. Night-shift work, sleep duration, daytime napping, and breast cancer risk. Sleep Med. 2015;16(4):462-8. https://doi.org/10.1016/j.sleep.2014.11.017

20. Blask DE. Melatonin, sleep disturbance and cancer risk. Sleep Med Rev. 2009;13(4):257-64. https://doi.org/10.1016/j. smrv.2008.07.007

21. Hansen $\AA$, Garde A, Hansen J. Diurnal urinary 6-sulfatoxymelatonin levels among healthy Danish nurses during work and leisure time. Chronobiol Int. 2006;23(6):1203-15. https://doi.org/10.1080/07420520601100955

22. Hersh C, Sisti J, Richiutti V, Schernhammer E. The effects of sleep and light at night on melatonin in adolescents. Hormones (Athens ). 2015;14(3):399-409. https://doi.org/10.14310/horm.2002.1564

23. Nielsen NR, Zhang ZF, Kristensen TS, Netterstrom B, Schnohr P, Gronbaek M. Self reported stress and risk of breast cancer: prospective cohort study. BMJ. 2005;331(7516):548. https://doi.org/10.1136/bmj.38547.638183.06 
24. Davies HW, Teschke K, Kennedy SM, Hodgson MR, Demers PA. A retrospective assessment of occupational noise exposures for a longitudinal epidemiological study. Occup Environ Med. 2009;66(6):388-94.

25. Andersen ZJ, Stafoggia M, Weinmayr G, Pedersen M, Galassi C, Jorgensen JT, et al. Long-Term Exposure to Ambient Air Pollution and Incidence of Postmenopausal Breast Cancer in 15 European Cohorts within the ESCAPE Project. Environ Health Perspect. 2017;125(10):107005. https://doi.org/10.1289/EHP1742

26. Gray JM, Rasanayagam S, Engel C, Rizzo J. State of the evidence 2017: an update on the connection between breast cancer and the environment. Environ Health. 2017;16(1):94. https://doi.org/10.1186/s12940-017-0287-4

\section{Johnni Hansen}

Danish Cancer Society Research Center,

Copenhagen, Denmark

[email: johnni@cancer.dk] 